\title{
Supplier Selection in Supply Chain Managment by Using ANP and Fuzzy TOPSIS
}

\author{
Ali A. Yahya Tabar and Hadi Charkhgard
}

\begin{abstract}
Nowadays supply chain management is one of the most important affairs that applying its new approaches is essential among competitive industries and markets. For any company, the most significant decision is to purchase goods, materials and services from suppliers. Now the better suppliers perform the better company do. So the role of suppliers is critical in the competitive markets. Supplier selection is the first step of the supply chain management. Supplier selection is a problem for any organization because of its role on reducing cost in the supply chain management. It is little complex because of existing various criteria and it is the multi criteria problem and there are experts in any company to make decision in accordance with multiple criteria. This paper proposed an integrated method using Analytic Network Process (ANP) and Fuzzy-Technique for Order Preference by Similarity to the Ideal Solution (FTOPSIS) .this paper used ANP to calculate the weights of each criteria of the model and for the sake of complexity in evaluation to prepare exact numerical values for the criteria is difficult, fuzzy TOPSIS is used in this paper to select the best supplier.
\end{abstract}

Index Terms-Component, ANP, fuzzy TOPSIS, supplier selection.

\section{INTRODUCTION}

A supply chain includes all groups involved to meet a customer needs. Supply chain needs to be managed for improving productivity. Managing the supply chain is gaining more and more focus in past two decades with rising global competition and expanding markets. Supply chain management (SCM) consists of many concepts and techniques. Information technology plays the most important role in SCM. Many companies focus on supply chain management because they understand that how much this kind of management could help them to survive and grow in the competitive markets. Appropriate supply chain is made by the strong links within and between various business entities. Serving the customer with the desired product within shortest possible time and at low cost is the key to success in the market. Suppliers and distributors are the closest links to the organization in the supply chain and contribute largely to be appropriate of the supply chain. The quality of suppliers affects directly organization'sperformance. In fact the suppliers cause directly the success or fail of an organization. However these days organizations can not supply anything they need, they need suppliers, so an appropriate supplier selection can help organizations to get their objectives.

Manuscript received August 7, 2012; revised September 28, 2012.

The authors are with the Industrial Engineering Department Sharif University of Technology Tehran, Iran (e-mail: aya6425@gmail.com, h.charkhgard@gmail.com).
During these years, supplier selection is a key factor for organizations. Supplier selection becomes one of the most essential functions to decrease material cost [1]. Fail in supplier selection causes deterioration in the throughout financial part of supply chain [2].

In SCM the evaluation of potential suppliers is based on multiple criteria than single factor-price [3] the dynamic environment that companies are and in the presence of many factors, both qualitative and quantitative, decision makers must select the best suppliers.

A lot of methods used in this area, Braglia [4] and

Talluri [5] used DEA method to evaluate the suppliers' performance. A Linear programming model is presented for supplier selection problem in the paper of Talluri [6]. Reference [7] shows mixed-integer linear programming model to select supplier. The model intends to maximize the revenue by determining the optimal order quantity and the optimal number of suppliers. Reference [8] applies a goal programming model for supplier selection problem. A multi-objective programming problem is modeled for supplier selection problem by Wadhwa and Ravindran [9]. Three objective functions are defined, to minimize the price, rejects, and lead time. Finally three solution methods were used to compare, such as weighted objective method, goal programming method, and compromise programming. Chan and Chan [10], Liu and Hai [11] used Analytic Hierarchy Process (AHP) to asses and select the suppliers. Bayazit [12] implemented an ANP model to extract the most appropriate suppliers. The model includes ten criteria that are categorized into two capability and performance clusters. Reference [13] indicates fuzzy theory in the proposed model. Cebi and Bayraktar [14] suggest integrated model using AHP and Goal Programming (GP). The weightings of suppliers are calculated by AHP and GP is used to select the suppliers. Mendoza and Ventura [15] presented a hybrid model to supplier selection problem. It includes AHP and mixed integer non-linear programming. This paper proposes an integrated model using ANP to calculate the weights of criteria and TOPSIS approach is used to select the most appropriate set of suppliers based on fuzzy theory because of being difficult to suggest the exact number when making paired comparison of criteria. This approach is applied because the computation procedure is straightforward and this method is completely rational [16]. The following shows that the rest of this paper: section 2 briefly discusses the supplier selection criteria. Section3 explains the definition of ANP and fuzzy TOPSIS. Section4 illustrates the detailed steps of proposed model for supplier selection problem, and the last section of the paper includes conclusion. 


\section{SuPPlier SElection CRITERIA}

Identification of criteria is an important step in the process of decision making and construction the structure of criteria is more important. Due to different fields that exist in businesses in the world, these steps are more difficult for supplier selection. A lot of criteria were defined in the literature. But in reality there are always some criteria that are determined by experts in decision making team and stakeholders.

A general flexible structure was constructed in this paper that covers all introduced criteria in the literature. The structure consists of three main categories: supplier status, delivery capability, and other. In the following these categories are described briefly.

\section{Supplier State (C1)}

This criterion includes three sub-criteria (production (Sc1), technical capability ( $\mathrm{Sc} 2)$, human resource capability $(\mathrm{Sc} 3)$ ). Supplier state indicates structural status of any organization.

\section{Delivery capability ( $C 2)$}

This criterion consists of three sub-criteria (service (Sc4), reliability delivering (Sc5), lead time (Sc6)).

\section{Other(C3)}

This criterion includes three sub-criteria (quality (Sc7), price $(\mathrm{Sc} 8)$, geography $(\mathrm{Sc} 9))$.

\section{METHODS}

\section{A. The ANP Method}

The Analytic Network Process (ANP) is widely used by decision makers. To make decision, especially in selection problem, several alternatives are evaluated by decision team according to some criteria which have different relationships. Analytic Hierarchal Problem (AHP) is first presented by Saaty [17] for decision problems which have hierarchal structure. In reality a lot of decision problems exist that do not have hierarchal structure; they include dependence and feedback. In fact ANP is better showed by a network that has clusters of elements than a hierarchy [17]. ANP is a method that considers outer dependence (interaction and dependence between clusters), inner dependence (interaction and dependence between elements in a same cluster), and feedback. ANP relaxes the linear assumption of relationships and accepts interrelationships between elements. Instead of on direction in hierarchy, it includes network with dependence and feedback [18].

In ANP models, the first step is to make supermatrix (W). This means for comparison the criteria in whole system. This step is performed through pairwise comparisons by asking "How much importance does a criterion have compared to another criterion with respect to our interests or preferences?" the relative value of importance can be provided applying a scale of 1-9 to show equal importance (1) to extreme importance (9) [19].

The next step is to calculate the weighted supermatrix. If the column sum of any column in supermatrix is greater than 1 , that column must be normalized. There is a close similarity between this step and the concept of Markov chain [19]. The last step is to compute the overall priorities. The weighted supermatrix is raised to a significantly large power that is called limiting power to compute the overall priorities by (1):

$$
\lim _{k \rightarrow \infty} W^{k}
$$

\section{B. The Fuzzy TOPSIS Method}

Fuzzy set theory is presented by Zadeh [20] .the most important ability of fuzzy set theory is to show imprecise data. This study applies Triangular Fuzzy Number (TFN) for fuzzy-ANP. The most important reason for using triangular fuzzy number is to be easy for decision team to calculate and constructing a model by triangular fuzzy number has demonstrated to be appropriate way to formulate decision problems where the information is imprecise [21]-[24]. Some concepts and definitions of fuzzy set theory are presented as below:

- A fuzzy set is represented by a membership function. A fuzzy set $\tilde{A}$ on $R$ is represented by its membership function $\mu_{\tilde{\mathrm{A}}}$ which is related to each element $\mathrm{x}$ in $\mathrm{X}$ a number between the interval $[0,1]$. The value of $\mu_{\tilde{A}}$ is associated with the grade of $\mathrm{x}$ in $\tilde{A}$.

- A triangular fuzzy number $\tilde{A}$ is represented by $(l, m, u)$ that is shown in Fig. 1. Where $l \leq m \leq u$. The parameter $l$ denotes the smallest possible value, the parameter $m$ is the most promising value, and the parameter $u$ is the largest possible value. The membership function for triangular fuzzy number is defined as (2).

- The mathematical operations of TFN $\tilde{A}_{1}=\left(l_{1}, m l, u l\right)$ and $\tilde{A}_{2}=\left(l_{2}, m 2, u 2\right)$ are represented as (3), (4), (5) and (6).

- A linguistic variable plays the most essential role in the fuzzy set theory that values of variable are linguistic terms, because it is so helpful in situations which are too difficult and too severe to say quantitative expression [25]. For instance the values of considered linguistic variable can be expressed by very low, low, medium, high, very - high, etc that values can also be presented by fuzzy numbers [16].

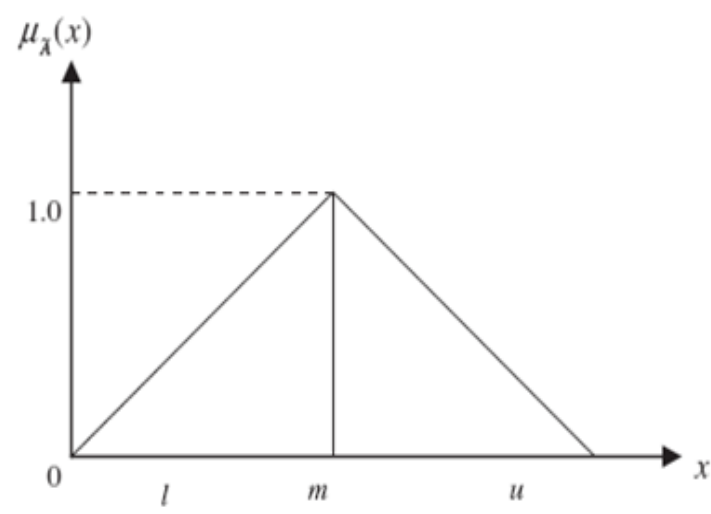

Fig. 1. The membership functions of the TFN.

$$
\tilde{x}_{i j} \mu \tilde{A}(x)\left\{\begin{array}{cc}
(x-1) /(m-1), & 1 \leq x \leq m \\
(u-x) /(u-m), & m \leq x \leq u<0 \\
0 & \text { otherwise }
\end{array}\right\}
$$


- $\tilde{A}_{1}=\left(l_{l}, m l, u l\right)$ and $\tilde{A}_{2}=\left(l_{2}, m 2, u 2\right)$ are two triangular fuzzy numbers, the vertex method is introduced to compute the distance between them.

$\mathrm{d}\left(\tilde{\mathrm{A}}_{1}, \tilde{\mathrm{A}}_{2}\right)=$

$$
\sqrt{\frac{1}{2}\left[(11-12)^{2}+(m 1-m 2)^{2}+(u 1-u 2)^{2}\right]}
$$

- (8) is applied to make the weighted fuzzy decision matrix.

$$
\tilde{N}=\left[\tilde{N}_{\mathrm{ij}}\right]_{n \times j}, i=1,2, \ldots, n \quad j=1,2, . ., m
$$

where

$$
\tilde{N}_{i j}=\tilde{x}_{i j} \times W_{\mathrm{i}}
$$

A set of ratings of $B_{j}=(j=1,2, . ., m)$ associated with criteria $C_{i}=(i=1,2, \ldots, \mathrm{n})$ called $\tilde{x}=\left(\tilde{x}_{i j}, i=1,2, \ldots, n, j=1,2, . ., m\right)$.

A set of importance weights of each criterion $W_{\mathrm{i}}=(i=$ $1,2, \ldots, n)[16]$.

Now fuzzy TOPSIS method steps can be represented as below ([17]; [16]):

Step1: Select the linguistic values $\left(\tilde{x}_{i j}, i=1,2, \ldots, n, j=\right.$ $1,2, . ., m)$ for alternatives considering criteria.

Step 2: Compute the weighted normalized fuzzy decision matrix by (8).

Step 3: Determine positive-ideal $\left(\mathrm{A}^{*}\right)$ and negative-ideal (A') solutions. The fuzzy positive-ideal solution and the negative-ideal solution are represented at (9) and (10).

$$
\begin{aligned}
& A^{\cdot}=\left\{\tilde{N}_{1}^{\cdot}, \tilde{N}_{2}^{\cdot}, \ldots, \tilde{N}_{i}^{\cdot}\right\}= \\
& \left.\left\{\left(\max _{j} m i j \mid i \in I^{\prime}\right), \times \max _{j} m i j \mid i \in I^{\prime \prime}\right)\right\}, \\
& i=1,2, \ldots, n, j=1,2, \ldots, m \\
& A^{\cdot}=\left\{\tilde{N}_{1}^{-}, \tilde{N}_{2}^{-}, \ldots, \tilde{N}_{i}^{-}\right\}= \\
& \left\{\left(\max _{j} m i j \mid i \in I^{\prime}\right), \times\left(\max _{j} m i j \mid i \in I^{\prime \prime}\right)\right\} \\
& i=1,2, \ldots, n, j=1,2, \ldots, m
\end{aligned}
$$

where $\mathrm{I}^{\prime}$ is related to positive criteria and I" is related to negative criteria.

Step 4: Compute the distance of each alternative from A* and $\mathrm{A}^{-}$by using (11) and (12).

$$
\begin{aligned}
& D_{j}^{\cdot}=\sum_{j=1}^{n} d\left(\tilde{N} i j, \tilde{N}_{i}^{\cdot}\right) \quad j=1,2, \ldots, m \\
& D_{j}^{-}=\sum_{j=1}^{n} d\left(\tilde{N} i j, \tilde{N}_{i}^{-}\right) \quad j=1,2, \ldots, m
\end{aligned}
$$

Step 5: Compute similarities to ideal solution.

$$
C C_{j}=\frac{D_{j}^{-}}{D_{j}^{-}+D_{j}^{\cdot}}
$$

\section{The Application of Proposed Model}

In the group working like this supplier selection problem, decision team's opinions are the main core of problem. But how to organize and transform to outcome is the most important affair. A model is proposed in this paper for supplier selection problem which transform opinions to considered result. This model consists of three main parts: determining the considered criteria, computation of the weights by ANP that is shown at Fig.2. Selection and ranking of suppliers are done by fuzzy TOPSIS method. In the first part considered criteria are determined by decision team. This study presented supplier selection criteria in section 2 by review in the literature. But some of them might not be appropriate for some businesses and specific criteria might be required to add. The next part is to calculate the weights of criteria by ANP. In this part decision team must make evaluations. Suppose that three suppliers for example S1, S2 and S3 exist and must be evaluated. In accordance with considered criteria, sub-criteria are compared with respect to their criteria; results are represented in Table I, Table II, and Table III.

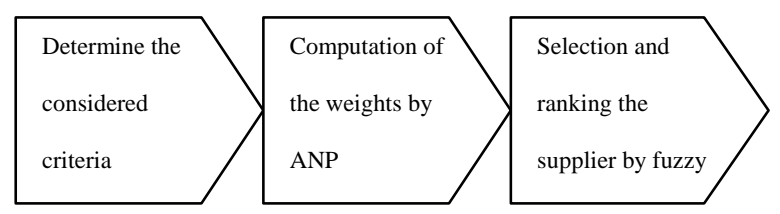

Fig. 2. Main stages of the proposed model.

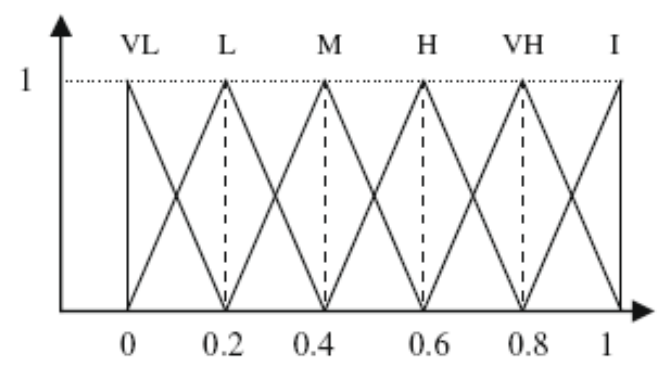

Fig. 3. Linguistic values [16]

Supposed suppliers are compared with respect to all sub-criteria. And then weighted supermatrix is obtained that is shown in Table IV, and the last step of this part is gained by (1). Supplier selection is done by using fuzzy TOPSIS method in the last part. Linguistic values are applied for evaluation of suppliers that the membership functions of these linguistic values are prepared at Fig. 3 and the triangular fuzzy numbers associated with these variables are provided in table V. In this part, supposed suppliers are evaluated by linguistic variables and fuzzy evaluation matrix is calculated. Then by using the weights calculated in the previous part, the weighted evaluation matrix is determined according to (8). 


\section{CONCLUSION}

In this paper, it is tried to show an easy way to solve supplier selection problem. The process of supplier selection is often complex and this study helps to make the process easy. Proposed method for ranking and selection is fuzzy TOPSIS, but this method needs to have weights of criteria and the ANP is selected to meet this request. $\mathrm{CC}_{1}, \mathrm{CC}_{2}$ and $\mathrm{CC}_{3}$ are equal to $.61255, .60923$ and .54142 respectively. Thus, the most appropriate supplier is $\mathrm{S} 1$.

\section{REFERENCES}

[1] R. F. Saen, "A new mathematical approach for suppliers selection: Accounting for non-homogeneity is important," Applied Mathematics and Computation, vol. 185, no.1, pp. 84-95, February 2007.

[2] A. Ceyhun and O. Irem, "A multicriteria sorting procedure for financial classification problems: The case of business failure risk assessment," in Proc. 6th International Conference on Intelligent Data Engineering and Automated Learning, Berlin, 2005, pp. 563-570.

[3] W. Ho, X. Xu, and P. K. Dey, "Multi-criteria decision making approaches for supplier evaluation and selection: A literature review," European Journal of Operational Research, vol. 202 , no. 1, pp. 16-24, April 2010.

[4] M. Braglia and A. Petroni, "A quality assurance-oriented methodology for handling tradeoffs in supplier selection," International Journal of Physical Distribution and Logistics Management, vol. 30, no. 2, pp. 96-111, 2000.

[5] S. Talluri and J. Sarkis, "A model for performance monitoring of suppliers," International Journal of Production Research, vol. 40, no. 16, pp. 4257-4269, November 2002.

[6] S. Talluri and R. Narasimhan, "A note on " a methodology for supply base optimization," IEEE Trans. on Engineering Management, vol. 52 no. 1, pp. 130-139, February 2005.

[7] G. H. Hong, S. C. Park, D. S. Jang, and H. M. Rho, "An effective supplier selection method for constructing a competitive supply-relationship," Expert Systems with Applications, vol. 28, no. 4, pp. 629-639, May 2005.

[8] B. Karpak, E. Kumcu, and R. R. Kasuganti, "Purchasing materials in the supply chain: Managing a multi-objective task," European Journal of Purchasing and Supply Management, vol. 7, no. 3, pp. 209-216, September 2001.

[9] V. Wadhwa and A. R. Ravindran, "Vendor selection in outsourcing," Computers and Operations Research, vol. 34, no. 12, pp. 3725-3737, December 2007.

[10] F. T. S. Chan and H. K. Chan, "Development of the supplier selection model - A case study in the advanced technology industry," Journal of Engineering Manufacture, vol. 218, no. 12, pp. 1807-1824, December 2004.
[11] F. H. F. Liu and H. L. Hai, "The voting analytic hierarchy process method for selecting supplier," International Journal of Production Economics, vol. 97, no. 3, pp. 308-317, August 2005.

[12] O. Bayazit, "Use of analytic network process in vendor selection decisions," Benchmarking: An International Journal, vol. 13, no. 5, pp. 566-579, 2006.

[13] C. T. Chen, C. T. Lin, and S. F. Huang, "A fuzzy approach for supplier evaluation and selection in supply chain management," International Journal of Production Economics, vol. 102, no. 2, pp. 289-301, August 2006.

[14] F. Çebi and D. Bayraktar, "An integrated approach for supplier selection," Logistics Information Management, vol. 16, no. 6, pp. 395-400, 2003.

[15] A. Mendoza and J. A. Ventura, "An effective method to supplier selection and order quantity allocation," International Journal of Business and Systems Research, vol. 2, no. 1, pp. 1-15, 2008.

[16] M. P. Amiri, "Project selection for oil-fields development by using the AHP and fuzzy TOPSIS methods," Expert System with Applications, vol. 37, no. 9, pp. 6218-6224, September 2010.

[17] The analytic hierarchy process. New York: McGraw-Hill., 1980.

[18] G. Büyüközkan and D. Öztürkcan, "An integrated analytic approach for Six Sigma project selection," Expert System with Applications, vol. 37, no. 8, pp. 5835-5847, August 2010.

[19] J. Huang, G. Tzeng, and C. Ong, "Multidimensional data in multidimensional scaling using the analytic network process," Pattern Recognition Letters, vol. 26, no. 6, pp. 755-767, May 2005.

[20] L. A. Zadeh, "Fuzzy sets", Information and Control, vol. 8, no. 3, pp. 338-353, June 1965.

[21] Y. H. Chang, H. Y. Chung, and S. Y. Wang, "A survey and optimization-based evaluation of development strategies for the air cargo industry," International Journal of Production Economics, vol. 106, no. 2, pp. 550-562, April 2007.

[22] Y. H. Chang and C. H. Yeh, "A survey analysis of service quality for domestic airlines," European Journal of Operational Research, vol. 139, no. 1 , pp. 166-177, May 2002.

[23] C. Kahraman, A. Beskese, and D. Ruan, "Measuring flexibility of computer integrated manufacturing systems using fuzzy cash flow analysis," Information Sciences, vol. 168, no. 1-4, pp. 77-94, December 2004.

[24] S. Onüt and S. Soner, "Transshipment site selection using the AHP and TOPSIS approaches under fuzzy environment," Waste Management, vol. 28, no. 9, pp. 1552-1559, 2007.

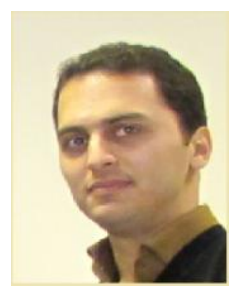

Ali A. Yahya Tabar Arabi studies Industrial Engineering in MS degree at Sharif University of Technology. His BS degree in Industrial Engineering was received in 2009 at Shomal University. His interest is around Supply Chain Management Reliability and Availability, Decision Making, and Operational Modeling. 